\title{
A Mild, Efficient, and Selective Debromination of vic-Dibromides to Alkenes with $\mathrm{Cp}_{2} \mathrm{TiCl}_{2} / \mathrm{Ga}$ System
}

\author{
Byung Woo Yoo, ${ }^{*}$ Seo Hee Kim, and Jun Ho Kim \\ Department of Advanced Materials Chemistry, Korea University, Jochiwon, Chungnam 339-700, Korea \\ *E-mail:bwyoo@korea.ac.kr \\ Received July 29, 2010, Accepted August 24, 2010
}

Key Words: Debromination, Alkene, Bis(cyclopentadienyl)titanium(IV) dichloride, Gallium

The combination of bromination and reductive debromination has been used to temporarily protect double bonds, to purify olefins, and to introduce a new double bond in organic synthesis. ${ }^{1}$ To date, a number of methods for effecting debromination have been developed in this regard, but most of these methods are associated with limitations regarding chemoselectivity, low yields, long reaction times, and elevated temperatures. ${ }^{2}$ Consequently a mild and efficient procedure for debromination of vic-dibromides continues to be developed. The chemical reactivity of $\mathrm{Cp}_{2} \mathrm{TiCl}_{2} / \mathrm{M}$ system $(\mathrm{M}=\mathrm{In}, \mathrm{Zn}, \mathrm{Mg}$, $\mathrm{Al}, \mathrm{Sm}$ ) has been the subject of considerable interest and the reducing ability of these systems has been extensively studied. ${ }^{3}$ Because of the close resemblance of gallium to indium and zinc in several respects, including first ionization potential, we considered that $\mathrm{Cp}_{2} \mathrm{TiCl}_{2} / \mathrm{Ga}$ system could also serve as a protocol for the debromination of vic-dibromides. In recent years gallium has drawn an increasing attention for its unique properties such as low toxicity and high stability in water and air compared with other metals. ${ }^{4}$ As in the case of indium, the reduction potential of gallium is not too negative $\left(\mathrm{Ga}: \mathrm{E}^{\mathrm{o}}, \mathrm{Ga}^{3+} / \mathrm{Ga}=-0.56 \mathrm{~V}\right.$; In: $\left.\mathrm{E}^{\mathrm{o}}, \mathrm{In}^{3+} / \mathrm{In}=-0.345 \mathrm{~V} ; \mathrm{Zn}: \mathrm{E}^{\mathrm{o}}, \mathrm{Zn}^{2+} / \mathrm{Zn}=-0.76 \mathrm{~V}\right)$ and thus it is not sensitive to water and does not form oxides readily in air. In continuation to our interest in exploring the utility of metalmetal salt system in organic synthesis, ${ }^{5}$ we report herein a mild and efficient procedure for debromination of vic-dibromides 1 to alkenes $\mathbf{2}$ with $\mathrm{Cp}_{2} \mathrm{TiCl}_{2} / \mathrm{Ga}$ system. The reaction can be generalized as in eq. 1. ${ }^{6}$ The new reagent system was generated by the addition of gallium to a stirred solution of bis(cyclopentadienyl)-titanium(IV) dichloride in THF under sonication. ${ }^{7}$ To guage the scope and limitations of this methodology, various substituted vic-dibromides were subjected to this protocal at room temperature. We have found that vic-dibromides on treatment with $\mathrm{Cp}_{2} \mathrm{TiCl}_{2} / \mathrm{Ga}$ system are smoothly converted into the corresponding alkenes in good to high yields. It has been reported that $\mathrm{Cp}_{2} \mathrm{TiCl}_{2} / \mathrm{Zn}$ system can be used for a reductive debromination of vic-dibromides to alkenes. ${ }^{8}$ In comparison with $\mathrm{Cp}_{2} \mathrm{TiCl}_{2} / \mathrm{Zn}$ system, the reaction using $\mathrm{Cp}_{2} \mathrm{TiCl}_{2} / \mathrm{Ga}$ system are fast and high-yielding. The high yields of the debromination products and short reaction time demonstrate the efficiency of this new method. To ensure the role of gallium,

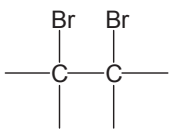

1

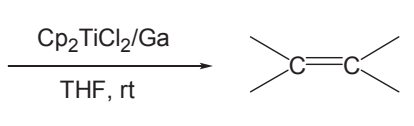

2 a controlled experiment was carried out using vic-dibromides with $\mathrm{Cp}_{2} \mathrm{TiCl}_{2}$ without gallium metal, which failed to yield any desired product. The optimum molar ratio of vic-dibromide to $\mathrm{Cp}_{2} \mathrm{TiCl}_{2}$ to gallium (1:1:2) is found to be ideal for the complete conversion of vic-dibromide $\mathbf{1}$ into alkene $\mathbf{2}$ in terms of yield and reaction time. And THF has been found to be the most suitable solvent for the reaction. Under sonication the reactions proceeded smoothly and efficiently with high yields. Thus, ultrasonic irradiation is necessary to accelerate the reaction. The result of the reaction is summarized in Table 1, where we examined a series of functionally and structurally various vic-dibromides. It is evident from the table that the reductive debrominations are chemoselective as aldehyde, keto, chloro, methoxy, carboxy and ester groups remained unaffected under the reaction conditions. Only trans olefins were obtained and no overreduction of the produced alkene was observed with any substrate. ${ }^{9}$ It was worth commenting that the sensitive carbonyl group remains intact without any further reduction under the reaction condition (entries 4-11). In comparison with other procedures, the present procedure reduced vic-dibromides more rapidly in higher yields and showed a good chemoselectivity. The major advantages of this methodology are mild reaction conditions, fast reaction time, high yields, and tolerance of various functional groups compared with existing reagents. Some of the vic-dibromides in the table are commercially available, or could be prepared conveniently from the corresponding precursors through known olefin halogenation reactions. ${ }^{10}$ Although the role of bis(cyclopentadienyl)titanium(IV) dichloride is still not clearly understood at this time, it is likely that reduction of titanium(IV) with gallium provides low valent titanium, which reacts with vic-dibromides $\mathbf{1}$ to give the corresponding alkenes 2. The reducing property exhibited by metal-metal salt combinations proceeds through transfer of one electron from the metal surface to the substrate. In such combinations elementary metal part needs to be more electropositive than the metal part of the salt. The involvement of low valent titanium resulting from the transmetallation of bis(cyclopentadienyl)titanium(IV) dichloride with gallium metal may be presumed. ${ }^{11}$ We have been able to demonstrate the utility of $\mathrm{Cp}_{2} \mathrm{TiCl}_{2} / \mathrm{Ga}$ system for effecting chemoselective debromination of vic-dibromides under the mild conditions.

In summary, we have discovered that $\mathrm{Cp}_{2} \mathrm{TiCl}_{2}$ /gallium system represents a mild and efficient protocol for reducing vic-dibromides to the corresponding alkenes with high yields. Although the scope and limitations were not fully established, 
Table 1. Reductive debromination of vic-dibromides with $\mathrm{Cp}_{2} \mathrm{TiCl}_{2} /$ Ga system.

(min)

${ }^{a}$ Isolated yields. The products are commercially available and were characterized by comparison of their spectral data with authentic samples. the present procedure offers an attractive alternative to the conventional methods with its mildness, rapidity and chemoselectivity as well as high yields. Further investigations of more useful applications are in progress.

Acknowledgments. This work was supported by Korea University Grant.

\section{References}

1. (a) For a review, see Tafesh, A. M.; Weiguny, J. Chem. Rev. 1996, 96, 2035. (b) Greene, T. W.; Wuts, P. G. M. Protective Groups in Organic Synthesis, 2nd ed.; New York, 1991. (c) Alfred, E. L.; Beck, B. R.; Voorhees, K. J. J. Org. Chem. 1974, 39, 1426.

2. (a) Buther, T. S.; Detty, M. R. J. Org. Chem. 1998, 63, 169. (b) Li, C. J.; Harpp, D. N. Tetrahedron Lett. 1990, 31, 6291. (c) Malanga, C.; Mannucci, S.; Lardicci, L. Tetrahedron 1998, 54, 1021. (d) Tanata, R.; Negoro, N.; Yanada, K.; Fujita, T. Tetrahedron Lett. 1996, 37, 9313. (e) Ranu, B. C.; Guchhait, S. K.; Sarkar, A. Chem. Commun. 1998, 2113. (f) Mathai, M.; Sching, K.; Miller, S. I. J. Org. Chem. 1970, 35, 1733.

3. (a) Lubineau, A.; Auge, J.; Queneau, Y. Synthesis 1994, 741. (b) Li, C. J. Tetrahedron 1996, 52, 5643. (c) Cintas, P. Synlett 1995, 1087.

4. (a) Vijay, N.; Sindu, R.; Jayan, C. N.; Bindu, S. P. Tetrahedron 2004, 60, 1959. (b) Lee, P. H. Bull. Korean Chem. Soc. 2007, 28, 17.

5. (a) Han, J. H.; Choi, K. I.; Kim, J. H.; Yoon, C. M.; Yoo, B. W. Synth. Commun. 2006, 36, 415. (b) Yoo, B. W.; Song, M. S.; Park, M. C. Synth. Commun. 2007, 37, 3089. (c) Yoo, B. W.; Park, M. C.; Shin, J. I. Bull. Korean Chem. Soc. 2009, 30, 1927. (d) Yoo, B. W.; Choi, J. W.; Kim, Y. S. Bull. Korean Chem. Soc. 2008, 29, 1655.

6. A typical procedure for the debromination of vic-dibromides is as follows: Gallium metal $(230 \mathrm{mg}, 2.0 \mathrm{mmol})$, bis(cyclopentadienyl)titanium(IV) dichloride (249 mg, $1.0 \mathrm{mmol}$ ) and THF $(4 \mathrm{~mL})$ were mixed under nitrogen atmosphere. The resulting mixture was stirred at room temperature for $0.5 \mathrm{~h}$ under sonication to get a solution of the low-valent titanium-gallium complex. meso1,2-Dibromo-1,2-diphenylethane (340 $\mathrm{mg}, 1.0 \mathrm{mmol})$ was then added to this solution and the reaction mixture was stirred for 10 $\mathrm{min}$ at room temperature. The solvent was removed under reduced pressure and the residue was extracted with ether, washed with brine, and dried over anhydrous $\mathrm{Na}_{2} \mathrm{SO}_{4}$. The crude product was purified by silica gel column chromatography (hexane:ethyl acetate $=15: 1)$ to afford trans-stilbene $(170 \mathrm{mg}, 94 \%)$. All of the products are commercially available compounds, and their identification was based on spectral comparison with authentic samples.

7. Sonication were carried out in a BRANSONIC ultrasonic cleaner bath, which delivered a $47 \mathrm{kHz}$ wave, with a fixed electrical power of 125 Watts.

8. Davies, S. G.; Thomas, S. E. Synthesis 1984, 1027.

9. (a) Hudlicky, T.; Sinai-Zingde, G.; Natchus, M. G. Tetrahedron Lett. 1987, 26, 5287. (b) Khurana, J. M.; Gogia, A.; Bankhwal, R. K. Synth. Commun. 1997, 27, 1801.

10. Vogel's Textbook of Practical Organic Chemistry, 4th ed.; Longman Group Limited: London, 1978; p 400.

11. Mourad, M. S.; Verma, R. S.; Kabalka, G. W. J. Org. Chem. 1985, 50,133 . 